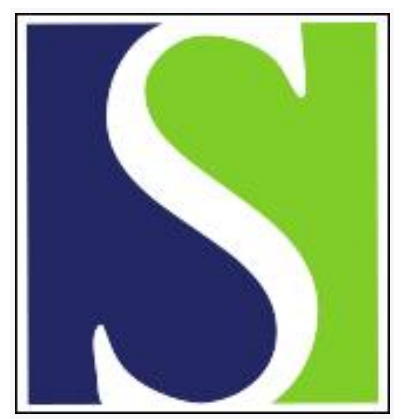

Scand J Work Environ Health 2012;38(3):187-192

https://doi.org/10.5271/sjweh.3296

Published online: 05 Apr 2012, Issue date: May 2012

Studying the effect of the psychosocial work environment on risk of ill-health: towards a more comprehensive assessment of working conditions

by Rugulies $R$

Affiliation: National Research Centre for the Working Environment, Lersø Parkallé 105, DK-2100 Copenhagen, Denmark. rer@nrcwe.dk

Refers to the following texts of the Journal: 2009;35(4):294-300 1988;14 suppl 1:27-28 2010;36(5):394-403 2010;36(6):435-444 2011;37(4):276-287 2011;37(5):359-362 2012;38(2):120-133 2012;38(3):218-227 2012;38(3):209-217 SJWEH Supplements 2008;(6):177-183 2006;32(6):421-430 2002;28(1):1-4

The following articles refer to this text: 2019;45(1):1-6; 2022;48(4):302-311

Key terms: absenteeism; assessment of working conditions; editorial; mental health; psychosocial work environment; risk of ill-health; sickness absence; sickness absence

This article in PubMed: www.ncbi.nlm.nih.gov/pubmed/22476352

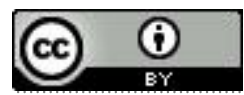




\section{Studying the effect of the psychosocial work environment on risk of ill-health: towards a more comprehensive assessment of working conditions}

The Nordic countries have a long tradition of research studying the impact of the psychosocial work environment on health (1, 2). Fittingly, the Scandinavian Journal of Work, Environment and Health has been a key place for the presentation and discussion of studies examining the complex relations between working conditions, psychological processes, and health and illness. Chances are high that this will continue in the foreseeable future as an increasing proportion of the workforce, particularly - but not exclusively - in high-income countries, is facing potentially health-affecting psychosocial working conditions, such as working with people in need, team work, demands for high flexibility, job insecurity, international competition, or working with tight deadlines - to name just a few examples (3). Additionally, mental ill-health, which is known to be caused to a substantial extent by adverse psychosocial circumstances in life (4), is on the rise to become the leading cause of disability-adjusted life years lost in high-income countries (5). Examining whether and how psychosocial working conditions contribute to mental ill-health, and ultimately how this knowledge can be used for preventive efforts, is an important task for occupational health research $(6,7)$.

Over the last decade, major improvements have been made in the designs of psychosocial work environment studies. Earlier research has often been hampered by an over reliance on cross-sectional data, with the immanent limitations in establishing temporality of exposure and outcome and drawing causal inference (8). Today, however, data from several large-scale cohort studies are available, not least in the Nordic countries. The number of cohort studies has grown to such an extent that a European Research Consortium recently launched a project on an "Individual-participant-data meta-analysis of working populations" (IPD-Work), aiming to synthesize the data from the numerous European psychosocial work environment cohort studies (9).

Despite this progress, there are still important methodological challenges that need to be tackled. A major concern is how the psychosocial work environment can be assessed in the most precise and unbiased way.

Self-administered questionnaires. By far, the most widely-used method for assessing the psychosocial work environment is the self-administered questionnaire. Several instruments with good psychometric properties have been developed, both for testing specific theoretical models $(10,11)$ and assessing the psychosocial work environment in all its broadness (12-14). Using self-reported data has many advantages. First, it is a convenient and cost-effective way to collect a lot of information from a large number of people, the latter being necessary when the aim is to investigate incident of disease. Second, workers are the obvious experts of their own workplaces; they are likely those who know most about their work environment. Third, questionnaires enable researchers to enquire about typical or average working conditions and are not restricted to the work environment of a specific day.

These important advantages must be balanced against one major disadvantage. The response in selfadministered questionnaires is in all likelihood not only driven by characteristics of the work environment (ie, the entity that is intended to be measured) but also by other factors, such as personal dispositions, mood, expectations, previous experiences, or health. This might cause both non-differential and differential misclassification, resulting in under- and overestimations of effects. For researchers mainly focused 
on how individual differences shape the perception and appraisal process of the person (15), the precise measurement of psychosocial working conditions might be of lesser concern. However, for researchers interested in the characteristics of the work environment that harm, protect or promote workers' health, the most accurate and valid assessment of psychosocial working conditions is a major concern.

This concern is, of course, not new. In the 1980s, scholars such as Kasl, Frese, and Zapf already warned against the naive use of self-reported exposure data in studies on psychosocial work environment and health $(16,17)$. Thus, the problem is not that the research community is unaware of the limitations of self-administered questionnaires; the problem is to find the right solutions. There are, for example, alternatives to self-administered questionnaires, but, not surprisingly, each alternative has its own challenges.

Workplace aggregation of self-reported data. The purpose of aggregating individual responses to group levels in the workplace (eg, departments or work groups) is that the influence of individual factors can be reduced and the shared work environment can be carved out. The method has been used in some studies (18-20), but has also been discussed controversially (21). Particular challenging is the identification of the organizational level at which individuals have a sufficient amount of shared work environment. Also, whereas certain workplace characteristics (eg, organizational justice) appear well-suited for workplace aggregation, other characteristics (eg, decision authority) might be better suited for aggregation at the job title instead of at the workplace level. To complicate things further, sometimes the non-shared work environment could be the most important exposure. Imagine a workplace where a high level of social coherence is achieved by the social exclusion of some selected employees. Whereas the social cohesion score of the workplace is likely high, the score of these selected employees is likely low. This might lead investigators to conclude that the scores of these employees are biased by individual characteristics, such as negative affectivity, whereas in fact the contrast between the high social cohesion score at the group level and the low score for these selected employees is the pivotal workplace exposure in this example.

Observer-based assessments. One of the most advanced methods for observer-based assessments of the psychosocial work environment is the RHIA/VERA method, which is a German acronym for "Regulationshindernisse in der Arbeitswelt/Verfahren zur Ermittlung von Regulationserfordernissen". The method, which is based on action-regulation theory, was developed by work and organizational psychologists in Germany in the 1980s $(22,23)$ and has been tested in several countries (24-26). A major advantage is that the objective of interest, the working conditions, are directly observed. A major disadvantage is that the assessment is time-consuming and costly. Moreover, psychosocial exposures, such as bullying, threats, or violence at work, which are important predictors of mental ill-health (27-29), are unlikely to surface in the presence of an observer. Further, although the method avoids bias resulting from employees' individual characteristics, bias resulting from observers' individual characteristics is possible.

Assessment by register data. Recently, Virtanen et al (30) used register data on hospital ward overcrowding as an indicator of high workload among hospital staff. The authors found a clear dose-response pattern between the level of ward overcrowding and risk of antidepressant treatment among the employees at these wards.

In this issue of the Scandinavian Journal of Work Environment and Health, Ervasti and colleagues (31) present a register-linkage study that examined the effect of the psychosocial work environment in schools on risk of sickness absence of teachers. This topic is highly relevant. Sickness absence has evolved as a major research theme, in particular in the Nordic countries $(32,33)$. Although sickness absence is a complex phenomenon, influenced not only by health but by other factors as well (34), it is nevertheless an excellent indicator of both physical and mental ill-health $(35,36)$. Human service work, including 
teaching, and the emotional demands associated with working with people, is suspected to increase risk of mental ill-health of employees and subsequent sickness absence $(37,38)$. Investigating this association is, however, difficult, because pre-clinical conditions of ill-health at baseline might cause participants to overestimate quantitative and emotional demands when working conditions are assessed by self-report.

Ervasti et al used register data on the proportion of pupils with special educational needs (SEN) at the schools as a measure of psychosocial working conditions. They found that risk of sickness absence increased with the percentage of SEN pupils, and that this association was stronger in schools with a high pupil-teacher ratio. Thus, the authors identified a prospective association between a specific working condition and risk of sickness absence. Their analyses also suggested a clear solution: increase teaching staff in schools with a high percentage of SEN pupils. Moreover, Ervasti et al (31) adjusted their analyses for average income level of residents in the school neighborhood, thereby addressing another important issue: the role of contextual factors in studies on psychosocial work environment and health (39).

Despite its merits, the article by Ervasti et al also illustrates the limitations of register-linkage studies. As the authors themselves point out, the study does not provide insight into the specific mechanism that links the proportion of SEN pupils to risk of sickness absence. A high proportion of SEN pupils might add to the quantitative workload of teachers, it might qualitatively change the teachers' work environment, for example by increasing social conflicts and decreasing social cohesion in the class, or it might generally cause a feeling of insufficiency among teachers who were not adequately trained to teach SEN pupils. Important effect modifiers might be the attitude and reactions of the other students and their parents towards SEN pupils and the school's written or unwritten policy of social inclusiveness. To investigate these and other potential mechanisms and explanations requires information beyond that available in registers. Thus register data might be most useful to assess quantitative and emotional demands at work, but they appear to be limited for the assessment of social relations, interactions, and conflicts.

Towards a more comprehensive assessment of working conditions. An object of research as complex as the psychosocial work environment requires thoughtful and comprehensive assessments. Because each assessment method has its advantages and disadvantages, combining methods might be a promising strategy. A few studies have used multi-method assessments. In a study with urban transit operators, Greiner and colleagues (25) found that observer-based but not self-reported stressors were associated with hypertension. When the authors analyzed interactions between observer-based and self-reported stressors, they found that hypertension was high among participants who had high levels of observer-based and low levels of self-reported stressors. Greiner et al (25) point out that this could indicate that adverse psychosocial working conditions might be particularly harmful when employees are unaware or in denial of the exposure.

In the study on hospital ward overcrowding and antidepressant treatment by Virtanen et al (30), job demands were also measured by self-report. In a further analysis, Kivimäki et al (40) showed that the part of the variation of self-reported job demands that was explained by ward overcrowding predicted sickness absence with psychiatric disorder, leading the authors to conclude that there was a prospective association between self-reported job demands and sickness absence that could not be explained by reporting bias.

These two examples illustrate some of the potential benefits of multi-method assessments of the psychosocial work environment. In the first example, the discrepancy in the results generated a new hypothesis on the potential role of unawareness and denial. In the second example, the concordance in the results provided important information on the validity of a self-administered questionnaire. In our endeavor to better understand how the psychosocial work environment can affect health and illness, we need more such studies.

Acknowledgement. Many thanks to the members of the "PIWA Research Group" at the National Research Centre for the Working Environment for valuable comments on an earlier draft of this editorial. 


\section{References}

1. Gardell B. Scandinavian research on stress in working life. Int J Health Serv. 1982;12(1):31-41. http://dx.doi.org/10.2190/ K3DH-0AXW-7DCP-GPFM.

2. Barling J, Griffiths A. A history of occupational health psychology. In: Quick JC, Tetrick LE, editors. Occupational health psychology. 2nd ed. Washington, DC: American Psychological Association; 2011. p21-34.

3. Kompier MA. New systems of work organization and workers' health. Scand J Work Environ Health. 2006;32(6):421-30. http://dx.doi.org/10.5271/sjweh.1048.

4. Kendler KS, Hettema JM, Butera F, Gardner CO, Prescott CA. Life event dimensions of loss, humiliation, entrapment, and danger in the prediction of onsets of major depression and generalized anxiety. Arch Gen Psychiatry. 2003;60(8):789-96. http://dx.doi.org/10.1001/archpsyc.60.8.789.

5. Mathers CD, Loncar D. Projections of global mortality and burden of disease from 2002 to 2030. PLoS Med. 2006;3(11):e442. http://dx.doi.org/10.1371/journal.pmed.0030442.

6. Netterstrøm B, Conrad N, Bech P, Fink P, Olsen O, Rugulies R, et al. The relation between work-related psychosocial factors and the development of depression. Epidemiol Rev. 2008;30(1):118-32. http://dx.doi.org/10.1093/epirev/mxn004.

7. Bonde JPE. Psychosocial factors at work and risk of depression: a systematic review of the epidemiological evidence. Occup Environ Med. 2008;65(7):438-45. http://dx.doi.org/10.1136/oem.2007.038430.

8. Kompier M. The psychosocial work environment and health--what do we know and where should we go? Scand J Work Environ Health. 2002;28(1):1-4. http://dx.doi.org/10.5271/sjweh.639.

9. Nyberg ST, Heikkilä K, Fransson EI, Alfredsson L, De Bacquer D, Bjorner JB, et al. Job strain in relation to body mass index: pooled analysis of 160000 adults from 13 cohort studies. J Intern Med. 2011 Nov 11. [Epub ahead of print]. http:// dx.doi.org/10.1111/j.1365-2796.2011.02482.x.

10. Karasek R, Brisson C, Kawakami N, Houtman I, Bongers P, Amick B. The Job Content Questionnaire (JCQ): an instrument for internationally comparative assessments of psychosocial job characteristics. J Occup Health Psychol. 1998;3(4):322355. http://dx.doi.org/10.1037/1076-8998.3.4.322.

11. Siegrist J, Starke D, Chandola T, Godin I, Marmot M, Niedhammer I, et al. The measurement of effort-reward imbalance at work: European comparisons. Soc Sci Med. 2004;58(8):1483-99. http://dx.doi.org/10.1016/S0277-9536(03)00351-4.

12. Hurrell JJ, Jr., McLaney MA. Exposure to job stress--a new psychometric instrument. Scand J Work Environ Health. 1988;14(Suppl. 1):27-28.

13. Wännström I, Peterson U, Åsberg M, Nygren Å, Gustavsson JP. Psychometric properties of scales in the General Nordic Questionnaire for Psychological and Social Factors at Work (QPS): confirmatory factor analysis and prediction of certified long-term sickness absence. Scand J Psychol. 2009;50(3):231-44. http://dx.doi.org/10.1111/j.1467-9450.2008.00697.x.

14. Pejtersen JH, Kristensen TS, Borg V, Bjorner JB. The second version of the Copenhagen Psychosocial Questionnaire. Scand J Public Health. 2010;38(Suppl 3):8-24. http://dx.doi.org/10.1177/1403494809349858.

15. Reme SE, Eriksen HR, Ursin H. Cognitive activation theory of stress - how are individual experiences mediated into biological systems? Scand J Work Environ Health. 2008;6(Suppl):177-83.

16. Kasl SV. Methodologies in stress and health: Past difficulties, present dilemmas, future directions. In: Kasl SV, Cooper CL, editors. Stress and health: Issues in research methodology. New York: Wiley; 1987. p307-18.

17. Frese M, Zapf D. Methodological issues in the study of work stress: Objective vs subjective measurement of work stress and the question of longitudinal studies. In: Cooper CL, Payne R, editors. Causes, coping and consequences of stress at work. Wiley series on studies in occupational stress. John Wiley \& Sons, Chichester, England; 1988. p375-411.

18. Christensen KB, Nielsen ML, Rugulies R, Smith-Hansen L, Kristensen TS. Workplace levels of psychosocial factors as prospective predictors of registered sickness absence. J Occup Environ Med. 2005;47(9):933-40. http://dx.doi. org/10.1097/01.jom.0000172864.16001.85.

19. Jensen HK, Wieclaw J, Munch-Hansen T, Thulstrup AM, Bonde JP. Does dissatisfaction with psychosocial work climate predict depressive, anxiety and substance abuse disorders? A prospective study of Danish public service employees. J Epidemiol Community Health. 2010;64(9):796-801. http://dx.doi.org/10.1136/jech.2008.083980.

20. Kolstad HA, Hansen ÅM, Kaergaard A, Thomsen JF, Kaerlev L, Mikkelsen S, et al. Job strain and the risk of depression: is reporting biased? Am J Epidemiol. 2011;173(1):94-102. http://dx.doi.org/10.1093/aje/kwq318.

21. Wang J, Patten SB. Re: ”Job Strain and the Risk of Depression: Is Reporting Biased?” Am J Epidemiol. 2011;174(1):125; author response 125-126.

22. Greiner BA, Krause N. Expert-observer assessment of job characteristics. In: Schnall PL, Belkic K, Landsbergis P, Baker $\mathrm{D}$, editors. The workplace and cardiovascular disease. State of the Art Reviews in Occupational Medicine. Philadelphia, PA: Hanley \& Belfus; 2000. p175-83.

23. Leitner K, Volpert W, Greiner B, Weber W, Hennes K. Analyse psychischer Belastungen in der Arbeit. Das RHIA Verfahren [Analysis of psychological strain at work. The RHIA method]. Köln: TÜV Rheinland; 1987.

24. Leitner K, Resch MG. Do the effects of job stressors on health persist over time? A longitudinal study with observational stressor measures. J Occup Health Psychol. 2005;10(1):18-30. http://dx.doi.org/10.1037/1076-8998.10.1.18.

25. Greiner BA, Krause N, Ragland D, Fisher JM. Occupational stressors and hypertension: a multi-method study using observer-based job analysis and self-reports in urban transit operators. Soc Sci Med. 2004;59(5):1081-94. http://dx.doi. org/10.1016/j.socscimed.2003.12.006.

26. Griffin JM, Greiner BA, Stansfeld SA, Marmot M. The effect of self-reported and observed job conditions on depression and anxiety symptoms: a comparison of theoretical models. J Occup Health Psychol. 2007;12(4):334-49. http://dx.doi. org/10.1037/1076-8998.12.4.334. 
27. Finne LB, Knardahl S, Lau B. Workplace bullying and mental distress - a prospective study of Norwegian employees. Scand J Work Environ Health. 2011;37(4):276-87. http://dx.doi.org/10.5271/sjweh.3156.

28. Rugulies R, Madsen IEH, Hjarsbech PU, Hogh A, Borg V, Carneiro IG, et al. Bullying at work and onset of a major depressive episode among Danish female eldercare workers. Scand J Work Environ Health. 2012;38(3):218-227. http:// dx.doi.org/10.5271/sjweh.3278

29. Madsen IEH, Burr H, Diderichsen F, Pejtersen JH, Borritz M, Bjorner JB, et al. Work-related violence and incident use of psychotropics. Am J Epidemiol. 2011;174(12):1354-62. http://dx.doi.org/10.1093/aje/kwr259.

30. Virtanen M, Pentti J, Vahtera J, Ferrie JE, Stansfeld SA, Helenius H, et al. Overcrowding in hospital wards as a predictor of antidepressant treatment among hospital staff. Am J Psychiatry. 2008;165(11):1482-6. http://dx.doi.org/10.1176/appi. ajp.2008.07121929.

31. Ervasti J, Kivimäki M, Kawachi I, Subramanian S, Pentti J, Ahola K, et al. Pupils with special educational needs in basic education schools and teachers' sickness absences - a register-linkage study. Scand J Work Environ Health. 2012;38(3):209217. http://dx.doi.org/10.5271/sjweh.3281

32. Laaksonen M, Mastekaasa A, Martikainen P, Rahkonen O, Piha K, Lahelma E. Gender differences in sickness absence--the contribution of occupation and workplace. Scand J Work Environ Health. 2010;36(5):394-403. http://dx.doi.org/10.5271/ sjweh.2909.

33. Aust B, Helverskov T, Nielsen MBD, Bjorner JB, Rugulies R, Nielsen K, et al. The Danish national return-to-work program - aims, content, and design of the process and effect evaluation. Scand J Work Environ Health. 2012;38(2):120-133. http:// dx.doi.org/10.5271/sjweh.3272.

34. Steensma H. Sickness absence, office types, and advances in absenteeism research. Scand J Work Environ Health. 2011;37(5):359-62. http://dx.doi.org/10.5271/sjweh.3185.

35. Ferrie JE, Vahtera J, Kivimäki M, Westerlund H, Melchior M, Alexanderson K, et al. Diagnosis-specific sickness absence and all-cause mortality in the GAZEL study. J Epidemiol Community Health. 2009;63(1):50-5. http://dx.doi.org/10.1136/ jech.2008.074369.

36. Melchior M, Ferrie JE, Alexanderson K, Goldberg M, Kivimäki M, Singh-Manoux A, et al. Using sickness absence records to predict future depression in a working population: prospective findings from the GAZEL cohort. Am J Public Health. 2009;99(8):1417-22. http://dx.doi.org/10.2105/AJPH.2008.142273.

37. Madsen IEH, Diderichsen F, Burr H, Rugulies R. Person-related work and incident use of antidepressants: relations and mediating factors from the Danish work environment cohort study. Scand J Work Environ Health. 2010;36(6):435-44. http://dx.doi.org/10.5271/sjweh.3049.

38. Hannerz H, Tüchsen F, Holbaek Pedersen B, Dyreborg J, Rugulies R, Albertsen K. Work-relatedness of mood disorders in Denmark. Scand J Work Environ Health. 2009;35(4):294-300. http://dx.doi.org/10.5271/sjweh.1329.

39. Rugulies R. Invited commentary: Structure and context matters--The need to emphasize "social" in "psychosocial epidemiology". Am J Epidemiol. 2012 Mar 5. [Epub ahead of print]. http://dx.doi.org/10.1093/aje/kws033.

40. Kivimäki M, Vahtera J, Kawachi I, Ferrie JE, Oksanen T, Joensuu M, et al. Psychosocial work environment as a risk factor for absence with a psychiatric diagnosis: an instrumental-variables analysis. Am J Epidemiol. 2010;172(2):167-72. http:// dx.doi.org/10.1093/aje/kwq094.

\author{
Reiner Rugulies \\ National Research Centre for the Working Environment \\ Lersø Parkallé 105, DK-2100 Copenhagen \\ [E-mail: rer@nrcwe.dk]
}


